\title{
Entre Brasília e o Broadway Boogie Woogie: a inter-representatividade na poesia de João Cabral de Melo Neto
}

\author{
Gustavo Suertegaray Saldivar
}

Resumo: O poeta João Cabral de Melo Neto surgiu no cenário literário brasileiro nos anos 40, filiado à Terceira Geração Modernista da Literatura Brasileira. Dono de uma poesia objetiva e de caráter concreto, voltada à valorização da forma e do rigor compositivo, e cuja temática abordava, além do próprio fazer poético, os aspectos regionalistas e a captação da realidade social, este poeta determinou novo marco histórico em nossa literatura pela singularidade de sua poesia. Tal singularidade é denotável pelas aproximações que podem ser feitas de suas obras com representações artísticas constantes da Arquitetura, das Artes Plásticas e da Música. Assim, este trabalho tem por objetivo demonstrar as possíveis relações destas vertentes artísticas com a poética de João Cabral de Melo Neto.

\begin{abstract}
The poet João Cabral de Melo Neto appeared in Brazilian literary scenario on the 40's, affiliated to Modernism's Third Generation of Brazilian literature. Owner of an objective and concrete poesy, related with structure valorization and composing rigidity, from whose subjects contained, besides the poetical work itself, regionalist aspects and the inveigling of his social reality, this bard sat up a new historical mark on Brazilian literature because of his singularity. This rareness is shown by the approaches between his books and the artistic representations on Architecture, on Arts and on Music. Therefore, this paper plans to show the feasible relations between these artistic veins and João Cabral de Melo Neto's poesy.
\end{abstract}

Keywords: Poetry; Relation; Arts; Artistic Representations
Palavras-chave: Poesia; Relação; Artes; Representações Artísticas

\author{
Representations
}

O poeta pernambucano João Cabral de Melo Neto surgiu no cenário literário brasileiro nos anos 40, filiado ao movimento que foi classificado pela historiografia literária como a Terceira Geração Modernista.

Os artistas deste momento cultural foram largamente influenciados por ensaios de escritores como Gilberto Freire (Casa Grande e Senzala) e Sergio Buarque de Holanda (Raízes do Brasil), entre outros, que tentaram entender a estrutura da sociedade nacional por meio de perspectivas históricas. Assim, o projeto ideológico dominante nesse período, relativamente aos escritores, foi o do Engajamento Intelectual.

\footnotetext{
* Gustavo Suertegaray Saldivar Aluno de Graduação do Bacharelado em Letras da UFRGS e bolsista do CNPq
} 
É neste quadro que aparece João Cabral de Melo Neto, com sua poesia objetiva e de caráter concreto, voltada à valorização da forma e do rigor compositivo, e cuja temática abordava, além do próprio fazer poético, os aspectos regionalistas e a observação da realidade social.

Sua produção foi, obviamente, resultado de muitas correntes poéticas que o antecederam. Dentre elas, pode-se citar o nome de Murilo Mendes, de cuja influência o próprio João Cabral deixou testemunhos. Todavia, não apenas de poetas vieram as linhas que formaram a escrita cabralina. É possível observar, em sua obra, o traço de outras vertentes artísticas, tais como da Arquitetura, das Artes Plásticas e da Música.

João Cabral buscou, na Arquitetura, novos modelos compositivos para expressar sua arte. Dessa procura resultou o fascínio do poeta pelas formas que caracterizaram o movimento arquitetônico do Modernismo, vertente preponderante no cenário construto-conceitual da primeira metade do século XX, na área. Mais especificamente, o poeta trouxe para suas obras o ideário do principal teórico do movimento, o arquiteto suiço-francês Charles-Edouard Jeanneret-Gris, conhecido pelo pseudônimo de Le Corbusier.

A respeito do suíço e de sua própria produção artística, o vate assim se pronunciou: "Para mim, a poesia é uma construção, como uma casa. Isso eu aprendi com Le Corbusier. A poesia é uma composição. Quando digo composição, quero dizer uma coisa construída, planejada - de fora para dentro" (SANTOS, 2002).

Em 1955, o arquiteto produziu o contraponto: um volume intitulado Le Poème de l'Angle Droit (O poema do ângulo reto), no qual procurou demonstrar a carga poética constante de suas construções, repletas de encontros ortogonais e formas regulares.

Outra característica conceitual comum a ambos os artistas encontra-se no fato de que suas produções foram consideradas, não apenas pela crítica, como também pelos próprios autores, 'máquinas'. Máquinas no sentido de serem estritamente funcionais e despojadas de quaisquer espécies de ornamentações, de superfluidades. O que resta é, obviamente, apenas o imprescindível.

Dessa forma, em uma construção courbesiana, tem-se uma máquina de habitar, e, na construção cabralina, tem-se uma máquina de comover, tendo ambos uma função absolutamente clara e, por vezes, determinada pela própria natureza de sua utilização. Note-se que o termo 'construção' é empregado, e repetido, de forma intencional, na busca deliberada de marcar o pensamento dos dois autores em relação às suas obras.

Este raciocínio pragmático leva à inegável conclusão de que, tanto os edifícios de um, quanto os poemas do outro, são apenas objetos sólidos e consistentes, concebidos com o 
intuito de preencher um espaço vazio, de ocupar um vácuo, e que obedecem, em seus processos de confecção, às mesmas leis geométricas e construtivas.

Abaixo seguem uma representação pictórica de um texto de João Cabral e um excerto de um objeto descritor do trabalho de Le Corbusier (o paradoxo não permite uma distinção muito clara entre uma obra e outra):

\begin{abstract}
A arquitetura como construir portas, de abrir; ou como construir o aberto; construir, não como ilhar e prender, nem construir como fechar secretos; construir portas abertas, em portas; casas exclusivamente portas e teto. $\mathrm{O}$ arquiteto: o que abre para o homem (tudo se sanearia desde casas abertas) portas por-onde, jamais portas-contra; por onde, livres: ar luz razão certa.
\end{abstract}

(MELO NETO, 1994, p. 345)

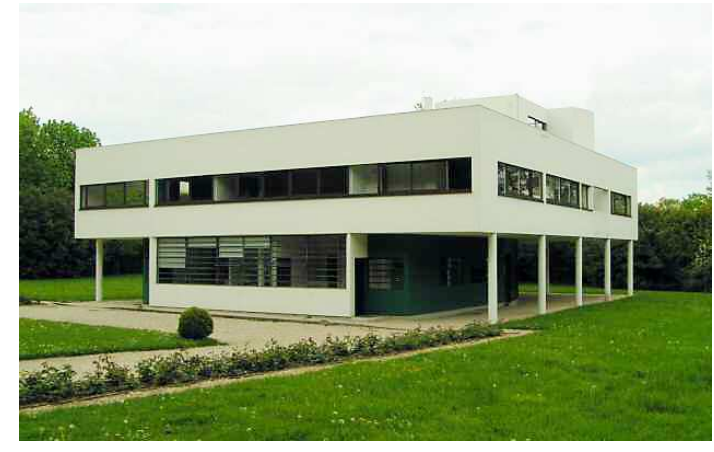

Fig. 1 - Le Corbusier, Villa Savoye

Por conta dessa simbiose lógico-formal, dá-se a associação entre o poeta pernambucano e o arquiteto de origem francesa. Entretanto, as ligações de João Cabral com a Arquitetura não se restringem a esse diálogo isolado.

A década de 50 trouxe ao Brasil um surto desenvolvimentista sem precedentes. Dentre as principais mudanças que se desenharam na realidade nacional pode-se destacar a construção da nova capital federal, Brasília, cidade que nasceu inspirada no ideário modernista de Le Corbusier, e cuja concepção e erigir competiram aos arquitetos brasileiros Oscar Niemeyer e Lúcio Costa.

A partir de uma análise sociológica deste fenômeno, observa-se uma relação interessante, qual seja: nos anos 50 começava a se intensificar o movimento de esvaziamento do campo e o conseqüente crescimento/inchamento dos centros urbanos, o chamado êxodo rural. A principal implicação dessa movimentação se concentrava na nova perspectiva do homem em relação ao espaço a ser ocupado e humanizado. Essa nova forma de organização suscitou alguns paradoxos.

O primeiro deles se encerra no fato de que as pessoas, acostumadas à vida no campo ou em pequenas comunidades, tiveram de se adaptar a essa nova existência. Mudaram os paradigmas das relações espaciais humanas, bem como os referentes simbólicos presentes nestas associações.

Outro contra-senso que se instaurou foi o da necessidade de criação de uma nova sistemática cultural inspirada no novo ambiente, uma cultura urbana. Para tanto, fez-se 
necessário repensar a tradição cultural preexistente para buscar, através desta, um ponto de ruptura. Ou seja, foi por meio do diálogo com o antigo, com o tradicional, que se formou uma nova idéia de sociedade, que surgiu para suplantar a noção mais tardia.

Brasília é, então, pensada e erguida levando em conta tais variáveis. Mas elas não são as adaptações mais relevantes. Historicamente, se dá outra situação bastante controversa: a área destinada ao erigir da nova capital, na porção geográfica central de nosso país, tinha uma densidade populacional ínfima, sendo vista como "terra a dominar", sob o ponto de observação sócio-geográfico. A “conquista” da região do baixo Tocantins foi tomada, então, como o último movimento de Entrada no País.

O que se tem, a partir disso, é o estabelecimento de uma nova cidade, calcada em conceitos construtivos e urbanos absolutamente inovadores, erguida em um ambiente resultante de uma operação eminentemente histórica de ocupação territorial. Brasília é o que se poderia chamar de um lapso de modernidade em meio ao arcaico, ou um arcaísmo imbuído de um intuito modernizador.

É neste momento, também, que João Cabral de Melo Neto está em plena atividade artística. E o ponto de encontro entre a obra cabralina e a concepção da nova capital está exatamente na reedição do paradoxo descrito acima, em relação à Brasília.

$\mathrm{O}$ poeta pernambucano foi um dos expoentes de uma geração de intelectuais que tinham um compromisso muito estreito com a divulgação e discussão da realidade de sua vida, de seu povo, de sua terra.

Sob essa perspectiva, João Cabral produziu inúmeras obras marcadamente sociais, cuja função era retratar as inóspitas condições de vida do homem nordestino. Tratava-se, pois, de uma temática singular e inédita. Da mesma forma, sua linguagem também transcendia os preceitos de época, sendo igualmente inovadora. A questão paradoxal se deu no âmbito da forma de suas construções, que não se alinharam ao pensamento formal corrente, que valorizava a quase total liberdade estrutural.

Ao contrário, o poeta buscou meios mais tradicionais, mais comuns, abrindo mão dos experimentalismos formais, tão em voga em sua época, para produzir uma poesia cujo conteúdo jamais encontrara paralelo na literatura brasileira, até aquele momento. É a representação, na escrita, do fenômeno sócio-antropológico de Brasília, ou seja, a poética de João Cabral também pode ser vista como um hiato de modernidade montada sobre uma estrutura arcaica.

Todavia, a representatividade na poética cabralina não se restringe à Arquitetura. João Cabral também se serviu de outras expressões artísticas na construção e idealização de sua 
lírica. Pode-se destacar, também, o diálogo produtivo e interessante que o pernambucano mantinha o pintor espanhol Joan Miró. Nesse sentido, a aproximação entre os autores pode ser pensada a partir de seus processos de criação.

Ambos os artistas procuraram, como requisito autocrítico básico, promover um distanciamento seguro de todas as formas e mecanismos construtivos preconcebidos, não apenas no tocante às influências externas, mas também no que concernia aos seus próprios parâmetros e às suas idéias, na construção de suas obras.

A pintura de um quadro ou de um painel pelo artista catalão e a fabricação de um poema pelo mestre pernambucano seguiam esquemas compositivos semelhantes, ou seja, ambos almejavam e valorizavam o esforço, o árduo trabalho, o fazer, no momento da gestação de suas obras, em um exercício que parecia relegar o resultado final a um plano secundário, inferior mesmo, em relação ao construir-se o poema, ou o quadro.

Era no construir-se o objeto que acontecia a conscientização dos artistas sobre as suas formas de pensar a atividade criadora. E o que acontecia a partir dessa tomada de consciência era a tentativa, por parte dos artesãos, de desfazerem-se dos pressupostos cristalizados e empedernidos pelo tempo e pelo uso repetitivo, o que incluía, naturalmente, suas próprias fórmulas. Resiste, em suas obras, uma busca pelo retorno ao estado mais livre do fazer artístico, o estado despojado, primitivo, primevo, do pensamento e sua realização na construção das obras.

Acerca dessas questões, o poeta referiu-se, em um estudo sobre o pintor catalão, ao modelo constitutivo negativo utilizado por este na confecção de suas pinturas. Negativo justamente no sentido da busca pelo esvaziamento semântico, pelo necessário estranhamento, por parte do espanhol, em suas manifestações formais. Ao abordar Miró, acabou tratando, inadvertidamente, sobre seu próprio fazer poético, vista a proximidade de seus esforços artísticos e sua afinidade de pontos de vista sobre suas atividades.

Diz-se, sobre o trabalho de Miró, que ele se utilizava de cinco estágios na construção de um quadro, e que, em cada um deles, buscava um maior distanciamento do que já vira e do que já fizera, ao longo de sua carreira, em termos de representações pictóricas. Utilizando-se do mesmo raciocínio, outro expediente do qual o mestre catalão lançava mão era o ato, simplório, porém inusitado, de passar o pincel para sua mão canhota, para criar o efeito do novo, do inesperado, e, ao mesmo tempo, opor-se ao costume da mão destra, cujo resultado poderia ser facilmente calculado e previsível.

Do pensamento de Miró sobre seu processo de criação, resultou, por exemplo, a obra intitulada "Chifres e constelações", que pode ser vista na ilustração abaixo: 


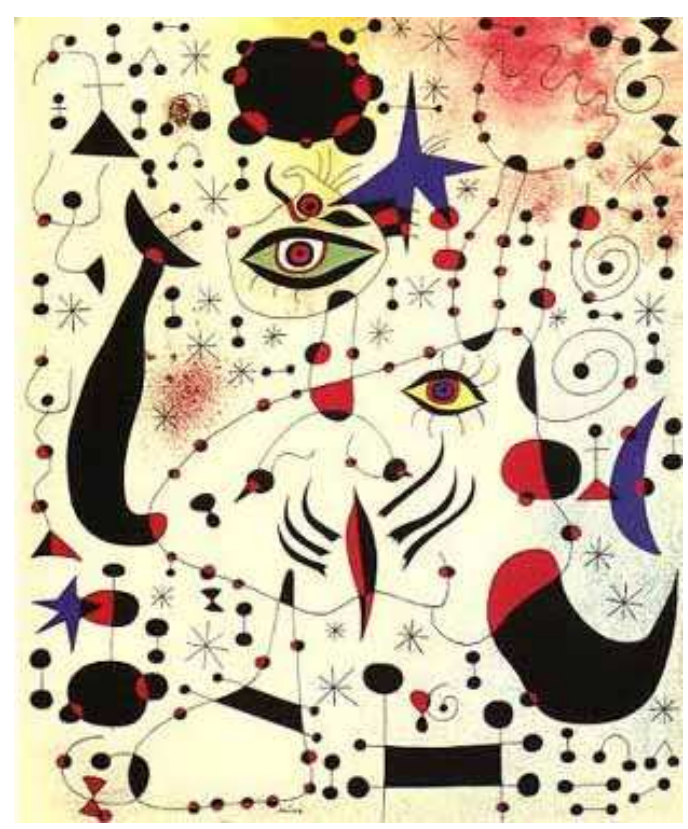

Fig. 2 - Joan Miró, Chifres e constelações.

Esta pintura, dentre outras características, revela a preocupação do artista espanhol com as formas, regulares e planas, bem como com a utilização de um número bastante reduzido de cores, denotando a forte tendência do autor à simplicidade. Tal propriedade também se repete na matematicidade e pureza das linhas, que perfazem absoluta maioria dos elementos de 'costura' entre os objetos gráficos, dos quais se pode depreender certo grau, reduzido, de organicidade. $\mathrm{O}$ que fica evidente, relativamente à representação acima, é o enorme esforço do pintor em apresentar um olhar distinto, por meio de escolhas formais também ímpares, sobre sua proposta de trabalho.

Da mesma maneira, o poeta João Cabral, por meio de seu incessante e quase obsessivo laboro, somado a um permanente estado de auto-julgamento e de auto-observação, buscou, ao imprimir cada palavra à folha branca, encontrar e demonstrar a inocência construtiva, $o$ sentido do inusitado, determinando a quebra com a preceptística, com a forma calcinada, engessada, limitante, automatizada, percebida pelo vate como a própria manifestação da nãoarte.

Além de Joan Miró, João Cabral de Melo Neto também rendeu homenagens a mais um artista plástico de sua contemporaneidade: Piet Mondrian.

Pieter Cornelis Mondriaan, dito Piet Mondrian, foi um pintor holandês que negou a herança artística de gênios como Vincent van Gogh e, calçado nos conceitos "subversivos" propostos pelas vanguardas européias de época, dirigiu suas pesquisas e produções para a decomposição de formas e para a abstração. 
A rebeldia de Mondrian atingiu o ponto de levá-lo a fundar uma nova corrente, o Neoplasticismo. Desse ponto em diante, o autor passou, tal como João Cabral com suas poesias, a valorizar o trabalho, e não apenas o resultado desse trabalho, isto é, a composição pictórica. As pesquisas em abstração o levaram à simplificação formal e estilística, ou seja, ao uso de linhas horizontais e verticais, e de esquemas de cores puras (primárias) ou de não-cores (branco, preto e cinza). Alguns exemplos de seus quadros podem ser vistos abaixo:

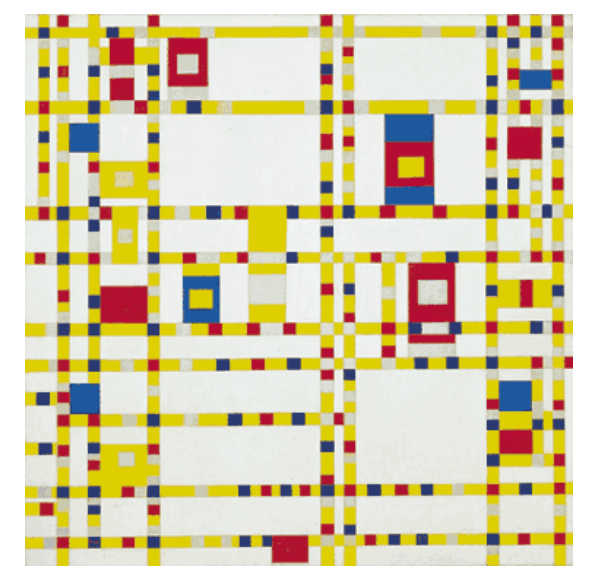

Fig. 3 - Piet Mondrian,

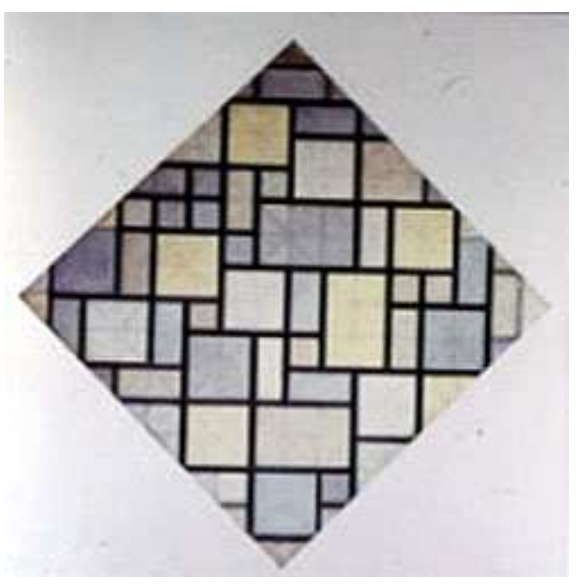

Fig. 4 - Piet Mondrian, Lozenge (1919)

Broadway boogie woogie (1943)

O diálogo entre o pintor batavo e o poeta pernambucano se deu, naturalmente, no sentido de ordem e de regularidade construtivas, bem como por seus sensos de espacialidade estrutural.

Também no relativo à forma de sua escrita, que pode ser vista como uma pintura negra sobre uma folha branca, e em sua semanticidade poética, arbitrária e propositadamente descolorida, monocromática, posto o enorme esforço do autor em depurar da poesia a sua carga puramente emotiva, pode-se observar a relação direta com as obras de Mondrian.

Outro ponto de contato interessante é o da geometria constante de ambos os artistas. É deveras baça e tênue a linha que separa a linguagem da imagem, da 'poesia ilustrada' de João Cabral, e da 'imagem lexical' presente em Piet Mondrian, no tangente às suas escolhas em termos de plasticidade.

Sobre a obra do pintor neerlandês, o pernambucano assim se pronunciou, em poema do qual se reproduz um excerto:

\footnotetext{
Então só essa pintura de que foste capaz, de que excluíste até o nada, por demais, e onde só conservaste o léxico conciso
} 
de teus perfis quadrados

(MELO NETO, 1994, p. 376)

Nesse poema também fica transparente a escolha dos dois autores pela linguagem artística do Minimalismo, que remete, evidentemente, à simplificação geométrica e à elementaridade em termos de materiais e de texturas, como já foi referido.

Também a Música encerra um interessante ponto de contato com a poesia de João Cabral de Melo Neto. Relativamente a esta arte, a busca pelos paralelismos se deu levando-se em conta o tema do Bolero, considerada a obra maior do compositor francês Maurice Ravel.

Uma das características comuns aos processos de construção do Bolero e das poesias cabralinas é o pensamento matemático que ambos os conjuntos comportam, no plano de sua concepção, o que lhes confere propriedades de organização, de precisão e de concretude.

No caso específico da Música, a matemática, requisito basilar e imprescindível à atividade, traveste-se na métrica, que representa o modo de organização dos elementos sonoros no verso musical e dos efeitos rítmicos em seu conjunto, em João Cabral, a matemática se apresenta sob a forma do rigor na composição e no tratamento formal dos versos, ou seja, na métrica, em sua poesia.

Outra peculiaridade comum ao Bolero e à produção do pernambucano se insere no fato de que em ambos é possível identificar o uso de estruturas compositivas semelhantes, no relativo à métrica e ao cânone.

Na composição de Ravel existe uma proposital preocupação quanto à repetição de séries de elementos, no sentido de instituir um cânone musical (o tema que passa por todas as vozes instrumentais estipuladas pelo compositor), como se pode observar nos trechos de partitura do Tema da Percussão, que perpassa, reiteradamente, toda a extensão da melodia, e no do Primeiro Tema, que é repassado por todas as vozes (ou instrumentos) do conjunto de execução em questão, dispostos a seguir:

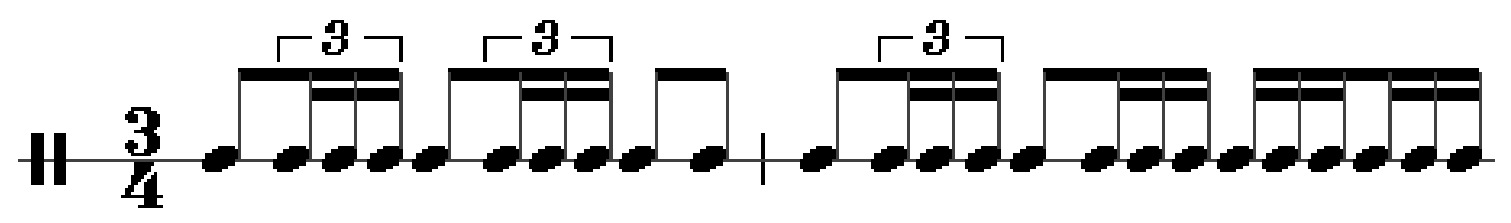

Fig. 5 - Maurice Ravel, Bolero (Tema da Percussão)

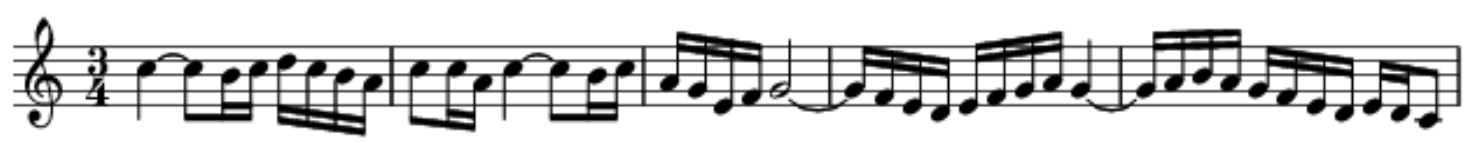

Fig. 6 - Maurice Ravel, Bolero (Primeiro Tema) 
Essa propriedade ímpar, somada ao fato de que a música vai adquirindo sempre uma maior intensidade, à medida que se aproxima do clímax - o que só se dá em seu final confere ao Bolero o título de o maior crescendo da Música mundial.

O mesmo ocorre de forma um tanto diferenciada na poética do pernambucano, que procurou estruturar determinados textos de modo a criar uma emulação de cânone, mas que, em verdade, constituiu grande quantidade de pequenas séries de repetição, incorporando aos poemas efeitos de Decomposição e Recomposição lingüísticos, tal como se pode observar no excerto abaixo:

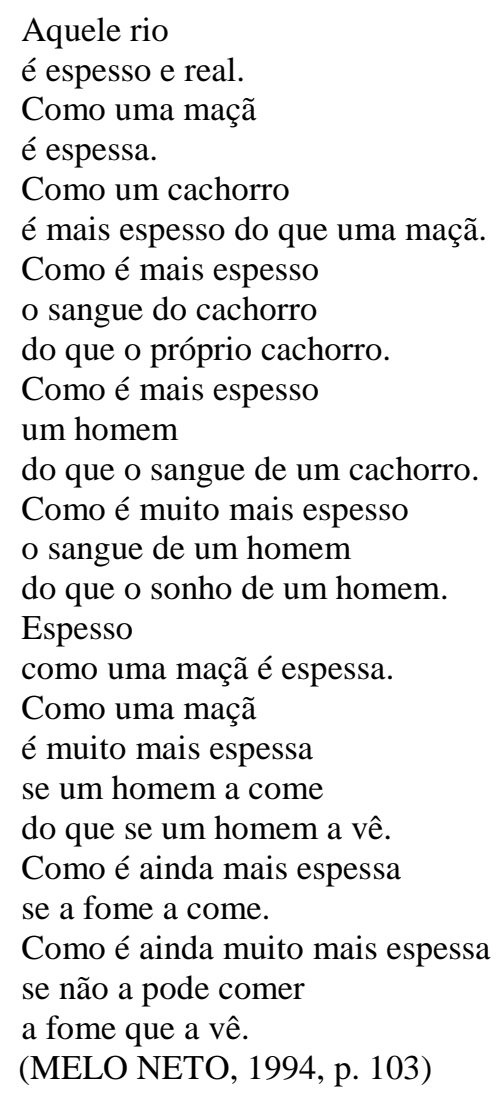

$\mathrm{O}$ que se infere, a partir de leituras deste pequeno trecho de $O$ cão sem plumas, levando-se em conta, naturalmente, a relação cânone/métrica, é que o poema cabralino não obedece, strictu sensu, à idéia de cânone, de replicação de uma célula. Todavia, quando se soma a essa idéia o conceito de métrica, tem-se um fenômeno peculiar que é o da alternância signo-semântica de termos, no corpo do texto.

Dessa forma, a Decomposição é vista exatamente como o corte ocasionado pela entrada do novo signo, que causará uma quebra na sequiência, instaurando nova série a ser trabalhada. Após o corte semântico inicial, configura-se a Recomposição, ou o reforço de uma idéia apresentada anteriormente. No excerto transcrito acima, são introduzidos, por exemplo, elementos como a maçã, o cachorro e o homem, que vão ser especificados e adquirirão novas 
significações (o pseudo-cânone), no desenrolar do poema, ocasionando nova síntese nessa relação semântico-dialética, e assim, sucessivamente, até o final do texto.

Concluindo, é inegável a importância da obra de João Cabral de Melo Neto no plano da literatura nacional, haja vista sua posição de permanente denúncia da cruel realidade de seu Nordeste. Também o é a relação deste poeta com o universo das demais manifestações artísticas com as quais conversava, em suas produções. Não se deve esquecer que João Cabral, do alto de sua genialidade e originalidade poéticas, é também produto do intrincado conjunto de fenômenos que forma a totalidade do conhecimento humano, e que, exatamente por conta disso, não é uma estrela solitária, e sim, mais uma em meio à constelação da humanidade.

\section{Referências}

LOPES, Cícero G. Conjunturas e disjunturas: tradição e ruptura. In: CAMPOS, Maria (Org). João Cabral em perspectiva. Porto Alegre: UFRGS, 1995. p.109-120.

MELO NETO, João C. de. Obra completa: volume único. Rio de Janeiro: Nova Aguilar, 1994.

MIRANDA, Antonio. [2004] Metapoesia de João Cabral de Melo Neto. Disponível em: <http://www.antoniomiranda.com.br/ensaios/METAPOESIA.pdf>. Acesso em 08 out 2006.

NUNES, Benedito. Joan Miró. In: NUNES, Benedito. João Cabral de Melo Neto. Rio de Janeiro: Vozes, 1971. p.185-189.

. Miró, Cabral e Ponge. In: NUNES, Benedito. João Cabral de Melo Neto. Rio de Janeiro: Vozes, 1971. p.157-161.

SANTOS, Luis A. B. [2002] Brasília, cidade arcaica. Disponível em: <http://www.imaginario.com.br/artigo/a0031_a0060/a0059.shtml>. Acesso em 08 out 2006. 